\title{
Myelitis, CTCAE
}

National Cancer Institute

\section{Source}

National Cancer Institute. Myelitis, CT CAE. NCI Thesaurus. Code C55459.

A disorder characterized by inflammation involving the spinal cord. Symptoms include weakness, paresthesia, sensory loss, marked discomfort and incontinence. 